\title{
Components of an effective large scale program for the prevention of inherited hemoglobin disorders; the paradigm of Greece
}

\author{
D. Loukopoulos' ${ }^{1}$ E. Voskaridou², M. Tsalkani² \\ ${ }^{1}$ Biomedical Research Foundation; Academy of Athens; ' 2 Laikon Thalassemia Center, Athens, \\ Greece
}

\begin{abstract}
Large scale prevention programs for Thalassemia major or Sickle cell disease have already been set up in several places with high frequency of the deleterious genes. The Greek health authorities realized the magnitude of the problem and allowed the creation of a National Thalassemia Center in 1972. The incidence of thalassemia in Greece varies from 1-2 per cent up to $15 \%$, the mean being around 8 per cent. With an annual number of births around 100,000, if no prevention measures are taken, the expected yearly number of newborns with thalassemia major in Greece should be of the order of 100-120. To these one should add a few decades of sickle cell patients, homozygotes or compound $\mathrm{HbS} / \beta$-thalassemia heterozygotes. The total number of patients with thalassemia major now surviving is estimated at 4,000 plus another $600-800$ patients with sickle cell disease. The National Thalassemia Center Center defined a network of peripheral Thalassemia Units in the major regional hospitals of the country, let them provide free carrier identification to couples requesting the test. When both partners were identified as carriers, they were given preliminary information locally and were referred to the Central Laboratory in Athens for further genetic counselling and, if so decided, prenatal diagnosis. Prenatal diagnosis was provided initially by fetoscopy and fetal blood biosynthesis; this approach was soon replaced by chorionic villi sampling and molecular techniques. The number of prenatal diagnoses carried out yearly over the last decade appears to cover the needs; the number of positive diagnoses is very close to the expected $25 \%$, which also excludes overdiagnosis. The overall evaluation of the the program is reflected in the number of infants who were admitted to the pediatric clinics of the country in need of transfusion over the years the program was functioning. In fact, over the past years this number has steadily decreased to approximately 10 missed diagnoses annually, but has not
\end{abstract}

Correspondence: D. Loukopoulos, Biomedical Research Foundation; Academy of Athens, Greece.

Key words: inherited hemoglobin disorders, prevention.

(C) Copyright D. Loukopoulos et al., 2011

Licensee PAGEPress, Italy

Thalassemia Reports 2011; 1(s2):e3

doi:10.4081/thal.2011.s2.e3

This article is distributed under the terms of the Creative Commons Attribution Noncommercial License (by-nc 3.0) which permits any noncommercial use, distribution, and reproduction in any medium, provided the original author(s) and source are credited.

Parts of this work were presented at the "12th International Conference on Thalassemia and Hemoglobinopathies”, Antalya (Turkey), 11-14 May 2011. reached zero as expected, after all this effort. The function of a comprehensive program for the prevention of thalassemia and $\mathrm{HbS}$ disease in Greece over the last 25 years has helped enormously in (a) avoiding birth of several hundreds of children with thalassemia major, thus (b) securing the use of the available resources for the optimal care of the patients who are living to-day, and (c) allowing thousands of couples at risk to give birth to healthy children.

\section{Introduction}

Thalassemia major or sickle cell disease result from the presence on the same individual of a major defect on both allelic genes coding for the $\beta$-chains of the human hemoglobin. This condition causes severe anemia with several complications and results in a painful, miserable, and non-productive life of the patients, along with a huge expense for their care, which can neither be optimal at all times nor easily met by the family and/or the national Health Authorities. For the time being, the possibilities of cure by bone marrow transplantation are limited to a few fortunate individuals only, while the long awaited gene therapy is still an experimental exercise. However, the fact that the trait of these disorders can be easily detected in the otherwise normal parents, makes prevention a feasible and realistic solution to the problem.

Prevention can be exerted in retrospective or prospective form; the former implies proceeding to carrier identification and eventually to prenatal diagnosis after the birth of an affected child, while in the latter all procedures take place before starting pregnancy. As expected, prospective prevention has been the start, across all places where the problem exists. In the past, unhappy couples carrying a thalassemic child often came to us complaining that nobody had ever given them the precious information; when the possibility of prenatal diagnosis became a reality, they did not complain; they demanded the test and have thus become instrumental in the acceptance of the procedure. Now that techniques are safe and allow prenatal diagnosis very early in pregnancy, I remember with a lot of admiration and respect those mothers who sought prenatal diagnosis in late pregnancy with fetoscopy and fetal blood biosynthesis. Be this as it may, retrospective prevention is out of question at this moment and our goal now focuses in offering it not only to the fortunate couples who have adequate education to report for the test, but also to all couples at risk across large masses of population.

An important prerequisite for the successful setting up of a prevention program across a large population is to define and convince the authorities who will sponsor it that this is well-timed, necessary, feasible, and cost effective. To this effect, authorities require adequate information regarding the the magnitude of the problem. This requires a census (or a reliable, as close as possible, estimation) of the surviving patients, establishment of the frequency of heterozygous carriers and calculation of the number of affected newborns which are expected to be born each year. It requires also an assessment of the available resources (hospitals and day-care Units) and, whenever feasible, a 
rough estimate of the expenses associated with the treatment of patients. Further calculations may project the cost on a time scale taking in consideration the ever increasing number of patients and the expanded survival of those already surviving. In addition, the fact that patients may not be fully productive, are unable to meet school or work obligations, and cause great difficulties to their parents who must often spend many hours daily for their care will certainly be a major factor in projecting the impact of the hemoglobinopathies in the given area.

These data are absolutely necessary to convince the policy makers; further support may be obtained by promoting the formation of Parents' Associations and have them put pressure on the Governments to initiate programs of prevention of the inherited hemoglobin disorders. Accumulating experience in many countries confirms the valu of these coordinated efforts. The argument to persuade the parents of affected children to collaborate and help is that preventing more births of affected children will allow re-allocation of funds to their own, surviving children.

A factor which may prove instrumental for initiating prevention programs on a large scale is the support of high level organizations. In the field of thalassemia, a major thrust for setting up the prevention program in Greece and other countries came from the document issued by the WHO Collaborative Group for the Prevention of the Inherited Haemoglobin Disorders organized and led by Anver Kuliev and Bernadette Modell in 1968. Along the same line, the fact that both thalassemia and sickle cell disease have been recognized by WHO and the United Nations as major health problems is of great value for convincing various national authorities and so are the precious efforts of TIF, OILD and other organizations.

Once the decision to implement a prevention program is made, sensitization and information of the involved population is the next step. In the past, at least for thalassemia in the Mediterranean countries, the problem was spontaneously solved because the appearance of several untreated patients was impressively abnormal and ugly and could not be easily overloooked; however now, in the areas where both prevention and treatment are effectively provided, patients are not recognized anymore and most people of the present generation completely ignore what thalassemia means.

Mass Media have a significant role in informing people; the problem is how to persuade them to donate some time to this effect. Posters and leaflets related to the problem are equally effective, but must be continuously available and renewed. In some countries the Church may play a significant role, especially when couples to be married apply for a prenuptial certificate. Be this as it may, there is little doubt that the major target for providing information is the School. This is not as easy as it may appear; experience shows that a major factor of success is not the inclusion of the topic of hemoglobinopathies in the books (usually in the secondary school) and other printed material; instead, the teachers must be adequately educated and enthusiastic to spread the concept to their pupils. Spread of information among various minority groups residing in foreign countries will not succeed unless educated social workers of the same origin and language are integrated in these communities.

As already said, this prospective approach is much preferable, because it can be offered to various groups of people (school, army, university) early enough to let them decide for their marriage, but it requires a flawless operation, which includes an easy access to the laboratories providing the test, ideally with no or minimal charge, at times which do not detract the examinees from their work, with kind and polite staff, and a definite answer on time. Association of the latter with additional information if both partners happen to carry the noxious genes is also a prerequisite and should be offered on a strictly personal basis, in keeping with the basic rule of counseling, i.e. explain but not direct.

In the past, most of these procedures were carried out retrospective- ly, i.e. on parents who had already an affected child; the search expanded, wherever possible, to other members of the family. This approach enabled the couples at risk to have a healthy child but did not help the overall prevention program. However, there are instances where this approach is the only potential solution to the program. This applies to the broad neonatal screening programs which are now in effect in several countries which harbour large numbers of indigenous or immigrant populations carrying the sickle cell gene and address the problem by identifying the homozygous sickle cell newborns in the maternities and then retrospectively examine parents and families in order to offer them the appropriate guidance for their next pregnancies.

Choice of the appropriate methodology is of utmost importance. Detection of the hemoglobinopathies which create public health problems is simple and non-expensive; hemoglobin electrophoresis and/or chromatography along with a sickling test are adequate to identify the carriers of hemoglobin S; a clearly low $\mathrm{MCH} / \mathrm{MCV}$ along with hemoglobin $\mathrm{A} 2$ determination on acetate strips or by chromatography will detect $\beta$-thalassemia in most cases. Measurement of iron and ferritin will easily exclude iron deficiency. For field studies an one tube solubility test or a one tube osmotic fragility test may readily identify the suspect cases; further investigation may then be completed in a proper reference laboratory. Applying complex molecular methods of acquiring sophisticated and very expensive apparatuses in small remote laboratories is disapproved because neither the staff can handle them well, nor the result which they are expected to provide justifies the expense. In addition, experience shows that whenever such an apparatus breaks down in a remote laboratory, the chances of having it repaired on time are minimal.

Carrier identification leads to the option of (a) not having children, (b) select another partner or (c) proceed to prenatal diagnosis. The choice depends on several very variable factors, such as the ethical, legal, social and family constraints which prevail in each population at risk as well as the technical feasibility of carrying out the procedure safely enough in the given environment. Under present conditions, prenatal diagnosis is carried out on fetal DNA extracted from chorionic villi cells which are obstetrically obtained at the 8-10th week of pregnancy. Identification of the noxious genes can be carried out usually following PCR amplification by allele specific hybridization or other molecular techniques.

Prenatal diagnosis has been accepted rather easily by most couples at risk in several communities and countries where the problem of thalassemia is pressing and it is gradually expanding wherever information and technical conditions make it possible.

Prenatal diagnosis of sickle cell disease at large lagged behind for various reasons : fear of interfering with eugenics and lack of compliance in several African-American communities, religious constraints in the Islamic world, technical difficulties in Africa. However, the desire of having a healthy child is so universal that sooner or later this procedure will become the only realistic solution for the populations which harbor high frequencies of the deleterious genes.

Organization of a prenatal diagnosis service is more complex than what appears to be a technical issue. Prospective mothers need a lot of psychological support to relieve their feelings of guilt to the affected sibling, to reinforce their decision to proceed when their spouse or his family do not concur, to relieve the fear for the examination, and to face selective termination of pregnancy when results show homozygosity. Be this as it may, evaluation of the so far obtained results leaves no doubt that the feasibility of prenatal diagnosis has been instrumental for the large scale acceptance of the concept of prevention because couples to be married know that even though they may both prove to be carriers there is a solution to giving birth to a healthy child.

The last component of a large scale prevention program is continuous quality control and monitoring. Any failure at any stage, be it because of negligence, incompetence, justified or not justified techni- 
cal problems, inadequate information or misconduct of the staff will seriously hamper the system for time periods much longer than what is needed to correct the failure itself. Quality control is ensured by frequent testing of commercially available blood samples or blood samples which are well tested in the mother laboratories and then sent out to peripheral Units for further testing. This procedure must be regularly carried out and carefully recorded. Statistics are necessary; they allow justification of the funds spent, identification of the weak points of the program, and planning of its next steps in a cost effective manner. An account of what has been planned vs what has been achieved is the final component of the program and sould not be neglected because it is the best way to reinforce and expand it further up.

Large scale prevention programs have already been set up in several places with high frequency of the deleterious genes. In most places, the programs were implemented by regional health authorities and dedicated colleagues caring for large numbers of thalassemia patients; in a few places the programs were gradually taken up by the national health authorities and expanded all over the country. Sardinia, Cyprus and Greece are examples of national programs, covering one million, one million and ten million inhabitants respectively. Within this context, in the rest of my talk, I will use the Greek experience to highlight the strong and weak points of our program and its final results.

Health authorities soon realized the magnitude of the problem and allowed the creation of a National Thalassemia Center, as an annex to the Laikon Hospital in Athens, in 1972. The incidence of thalassemia in Greece, a country of 10 million people, varies from 1-2 per cent in the mountainous regions up to $15 \%$ in the fertile valleys of Southern Peloponnesus, Thessaly, and Arta, the mean being around 8 per cent. This means that, with an annual number of births around 100,000, if no prevention measures are taken, the expected yearly number of newborns with thalassemia major should be of the order of 100-120. To these one should add a few decades of sickle cell patients, homozygotes or compound $\mathrm{HbS} / \beta$-thalassemia heterozygotes, born to inhabitants of some well known foci with high incidence of the sickle cell gene. The total number of patients with thalassemia major now surviving is estimated at 4,000 plus another $600-800$ patients with sickle cell disease. Persons who have been instrumental in setting up the prevention program have been professor Spyros Doxiades, acting at the right moment as Minister of Health, and professor Phaedon Fessas, who preached at the right moment the need for implementing this program. The concept was materialized through the effort of several colleagues, who cannot be cited by name here. The Center defined a network of peripheral Thalassemia Units in the major regional hospitals of the country, provided them with the appropriate personnel and laboratory facilities, ensured their training and quality control, and let them provide free and reliable carrier identification to all couples requesting the test. When both partners were identified as carriers, they were given preliminary information locally and were referred to the Central Laboratory in Athens for further genetic counselling and, if so decided, prenatal diagnosis. Sensitization and information were achieved through posters, leaflets, talks at various population groups, and by introducing a chapter on thalassemia in the high school curriculum. Obstetricians have also significantly contributed by referring pregnant women for carrier identification not only because of interest but also because of the potential legal consequences. Of the couples referred to the Center for genetic counselling almost all opted for prenatal diagnosis. The latter procedure has been carried in the department of Obstetrics of the Athens Medical School over several years; subsequently, a large number of chorionic samplings is carried out in various private clinics of Athens who send the obtained material to the Center for further study. I personally disagree with this procedure because of the risks it may hide.
The following slides summarize this activity. Prenatal diagnosis was provided initially by fetoscopy and fetal blood biosynthesis; this approach was soon replaced by chorionic villi sampling and molecular techniques as soon as the latter were brought into practice. The number of prenatal diagnoses carried out yearly over the last decade appears to grossly cover the needs; the number of positive diagnoses is steadily very close to the expected $25 \%$, which also excludes overdiagnosis. The overall evaluation of the the program is reflected in the number of infants who were admitted to the pediatric clinics of the country in need of transfusion over the years the program was functioning. In fact, as the last slide makes evident, over the past years this number has steadily decreased to approximately 10 missed diagnoses annually, but has not reached zero as expected, after all this effort. Recorded reasons for this partial success include several errors in carrier identification (expecially when this was done i private laboratories), a few errors in prenatal diagnosis (mainly those carried out by fetal blood biosynthesis), denial of elective abortion for religious or personal reasons, and last but not least, failure to sensitize and bring into the prevention system of several immigrants (mainly from Albania, who came in large numbers into Greece over the past years) or Gypsies, whose approach has been difficult if not impossible.

Be this as it may, the above account leaves no doubt that the function of a comprehensive program for the prevention of thalassemia and $\mathrm{HbS}$ disease in Greece over the last 25 years has helped enormously in (a) avoiding birth of several hundreds of children with thalassemia major, thus (b) securing the use of the available resources for the optimal care of the patients who are living to-day, and (c) allowing thousands of couples at risk to give birth to healthy children.

Undoubtedly, results in Sardinia and Cyprus, as well as in other regions are similar or even better; however, in the case of Greece, the fact that the program has covered effectively a whole nation strongly supports the implementation of other large scale systems in other countries (India, North Africa, the Middle East and other), where the high frequencies of inherited hemoglobin disorders demand immediate control.

\section{References}

1. Colah R, Gorakshakar A, Nadkarni A. Global burden, distribution and prevention of $\beta$-thalassemias and haemoglobin e disorders. Expert Rev. Hematol, 2010,3 :103-117.

2. Cousens NE, Gaff CL, Metkalfe SA, Delatycki MB. Carrier screening for $\beta$-thalassemia: a review of international practice. Eur J Hum Genet., 2010,18:1077-83.

3. Kollia P, Karababa $\mathrm{Ph}$, et al. $\beta$-thalassaemia mutations and the underlying $\beta$ gene cluster haplotypes in the Greek population. Gene Geogr., 1992,6:59-70.

4. Loukopoulos D, Karababa Ph, Antsaklis A, et al. Prenatal diagnosis of thalassemia and $\mathrm{HbS}$ syndromes in Greece: an evaluation of 1500 cases. Ann N Y Acad Sci, 1985,445:357-375.

5. Loukopoulos D. Current status of thalassemia and the sickle cell syndromes in Greece. Semin Hematol, 1996,33:76-86.

6. Malamos V, Fessas Ph, Stamatoyannopoulos G. Types of thalassaemia-trait carriers as revealed by a study of their incidence in Greece. Br J Haematol, 1962,8:5-14.

7. WHO Working group. Hereditary anaemias: genetic basis, clinical features, diagnosis and treatment. Bull World Health Organ, 1982,60:643-660. 